\title{
Quality Characteristics of Freeze-Dried, Irradiated or Freeze- Dried-Irradiated Cooked Hamburger Patties Formulated with a Novel Fat Substitute and Plum Extract For the International Space Station
}

\author{
E. J. Lee and D. U. Ahn \\ NASA Food Technology Commercial Space Center \\ Department of Animal Science, lowa State University
}

Copyright $\odot 2004$ SAE International

\begin{abstract}
The effect of adding fat substitute or plum extract on quality characteristics of frozen, freeze-dried, irradiated, or freeze-dried and irradiated cooked beef patties were determined to enhance the quality characteristics of ready-to eat (RTE) hamburger beef patties for NASA astronauts. Non-irradiated and irradiated controls (none added), $10 \%$ fat substitute Fantesk ${ }^{\mathrm{TM}}$-added and $2 \%$ plum extract-added treatments were prepared and irradiated frozen at 0 or $44 \mathrm{kGy}$ using a Linear Accelerator. Lipid oxidation, volatile profiles, color, texture, proximate analysis and sensory characteristics of cooked hamburger beef patties were determined after 0 and 30 days of storage at $-20^{\circ} \mathrm{C}$ (for frozen samples) or room temperature (for freeze-dried and irradiated samples).
\end{abstract}

Cooked beef patties added with fat substitute or plum extract had higher moisture content and carbohydrate, but lower lipid content than that of control treatment. Addition of plum extract improved the stability (TBARS values) of cooked beef patties during the 30-day storage, but the effects of processing treatments were stronger than that of lipid content. The volatile profiles of all cooked beef patties with different additive treatments were similar at day 0 , but changed dramatically after 30 day storage depending upon processing treatments.

Addition of $10 \%$ fat substitute did not influence the sensory characteristics of RTE hamburger beef patties, but juiciness was increased by plum extract. Processing treatments, however, were more important in the quality of cooked hamburger patties than additive treatments.

\section{INTRODUCTION}

Space food has been developed since astronaut John Glenn, who was the first American to orbit the Earth, ate some food in the weightless conditions of Earth orbit. The important factors for designed space food systems are low weight and long shelf-life. For example Shuttle, International Space Station (ISS), and planetary outpost have 9 month, 1 year, and 3-5 year shelf life requirements. Rehydratable foods, retort pouches for thermostabilized foods, and irradiated foods are used by NASA for space food. For ISS expedition crews the greatest request is food with improved mouth feel and taste.

Reduction in the fat content of hamburgers without compromising desirable quality characteristics is important to increase their acceptability by NASA astronauts as well as consumers on earth. The drastic reduction in fat content of beef for a marketable health image of hamburgers can result in a "dry" unpalatable product. Fat substitute Fantesk ${ }^{\mathrm{TM}}$ (Heritage Fare Technology, Cleveland, $\mathrm{OH}$ ) and plum extract pureed in meat product formulation can eliminate this quality defect. A novel fat substitute, Fantesk ${ }^{\mathrm{TM}}$ is a uniformly dispersed oil phase (10 to $50 \mu$ droplets) within a carbohydrate matrix (Garzon et al. 2003). Therefore it must naturally bind moisture and thus maintain the desirable texture and mouth feel consumers expect in a juicy hamburger. Also, the addition of the fat substitute to ground beef can reduce the fat content of the hamburger patties. This reduction in fat content should decrease the extent of off-odors generated from lipid oxidation during irradiation. Plum extract contains sorbitol, a known humectant, which naturally binds moisture and thus has the potential to alleviate the "dry" mouth-feel in low fat contents meat. The addition of plum extract to ground beef resulted in the production of hamburgers with a mouth-feel and texture that closely simulated the presence of fat in the cooked meat (Anon 1998). Decker (1999) reported that moisture retention of hamburgers with added plum puree designated by the USDA for the school lunch program was improved by $15.8 \%$ in precooked patties reheated to $102^{\circ} \mathrm{C}$ and held warm for up to 4 hours. More importantly, plum extract contains antioxidants (Keeton et al. 2001); therefore, it can 
reduce the development of off-odors from lipid oxidation in this meat product during irradiation.

Irradiation produces a characteristic aroma and alters meat flavor, which both significantly impacts consumer acceptance. The principle of irradiation using electron beam is that a stream of high-energy electrons propelled out of an electron gun is absorbed by materials in which the ionizing energy becomes reactive ions or free radicals (Woods and Pikaev 1994; Josephson and Peterson 2000). Hydroxyl radicals produced by ionizing radiation can increase lipid oxidation (O'Connell and Garner 1983; Thakur and Singh 1994), and myoglobin and fat oxidized by these free radicals in irradiated meat cause discoloration, rancidity, and off-odor in meat (Murano 1995).

The objective of this study was to determine the effect of fat substitute Fantesk ${ }^{\mathrm{TM}}$ and plum extract on quality characteristics of a freeze-dried, irradiated, or freezedried and irradiated cooked beef patties typically used by NASA astronauts. Lipid oxidation, volatiles, proximate analysis, and the sensory characteristics of hamburger patties formulated with or without fat substitute and plum extract were evaluated during storage.

\section{MATERIALS \& METHODS}

\section{SAMPLE PREPARATION - Raw beef was purchased from the lowa State University Meat Laboratory. Fat substitute FanteskTM was obtained from the Heritage Fare Ltd (Cleveland, $\mathrm{OH}$ ) and plum extract puree was obtained from the California Plum Board (Sunsweet Growers Inc., Yuba City, CA). Plum extract was dissolved in distilled wate before use. Fresh ground beef (80\% lean) was used to prepare hamburger patties for control (no fat substitute and plum extract added) and $90 \%$ lean meat was used for $10 \%$ fat substitute \\ FanteskTM or $2 \%$ plum extract treatments.}

For Fantesk ${ }^{\mathrm{TM}}$ treatment, the fresh raw beef and fat substitute were ground through a $3-\mathrm{mm}$ plate and then the ground beef and fat substitute (10\% of meat) were mixed for about $3.0 \mathrm{~min}$ in a mixer. For plum extractadded patties, plum extract ( $2 \%$ of meat weight) was dissolved with 4 vol. of deionized water, added to ground beef ( $90 \%$ lean), and mixed for 3 min to ensure uniform distribution of plum extract solution. The mixtures were chilled and patties (110 g) were prepared using an automatic patty machine.

Patties were weighed for cooking yield. Patties were cooked in a convection oven at $175^{\circ} \mathrm{C}$ to an internal temperature of $75^{\circ} \mathrm{C}$. Internal temperatures of meat during cooking were monitored with thermocouples connected to digital read-out devices. All the cooked meat patties were cooled then vacuum-packaged in high-oxygen-barrier bags (nylon/polyethylene, $9.3 \mathrm{~mL}$ $\mathrm{O}_{2} / \mathrm{m}_{2} / 24 \mathrm{~h}$ at $0{ }^{\circ} \mathrm{C}$; Koch, Kansas City, MO, USA) immediately after cooking to minimize oxidative changes during handling and storage before test. The cooked meats were refrigerated overnight before 0 -day chemical analyses and subsequent processes. Proximate analysis (moisture, protein, fat, and ash), volatile profiles, lipid oxidation and sensory characteristics of cooked patties were determined at 0 day.

The cooked patties were frozen, freeze-dried (FD), irradiated (IR), or freeze-dried and irradiated (FD+IR). Freeze-drying of patties was done using a Virtis freezedryer (Ultra-35 8 shelf unit, Virtis Inc.) without nitrogen flush of the chamber as recommended by NASA. Samples for freeze-drying were held at $-20^{\circ} \mathrm{C}$ in a walkin freezer prior to loading. Temperature of freeze dryer shelves were held initially at $<0^{\circ} \mathrm{C}$ until a vacuum reading of $<100$ millitorr was achieved (approximately 1 hour after loading) and then raised to $+26^{\circ} \mathrm{C}$ for duration of run. After freeze-drying, patties were individually vacuum-packaged in high-oxygen-barrier bags.

For irradiation, frozen samples in individual vacuum packs were irradiated at an average dose of 0 or $44 \mathrm{kGy}$ as recommended by NASA using a Linear Accelerator (Surebeam; Chicago, IL). The energy and power level used were $10 \mathrm{MeV}$ and $10 \mathrm{~kW}$, respectively, and the conveyer speed was $1 \mathrm{ft} / \mathrm{min}$. To confirm the target dose, 2 alanine dosimeters per cart were attached to the top and bottom surface of a sample. The alanine dosimeter was read using a 104 Electron Paramagnetic Resonance Instrument (Bruker Instruments Inc., Billerica, MA, USA). The $\mathrm{max} / \mathrm{min}$ ratio was approximately 1.18 (avg.).

Samples with frozen treatment were stored in a freezer at $-20^{\circ} \mathrm{C}$, whereas $\mathrm{FD}, \mathrm{IR}$ and $\mathrm{FD}+\mathrm{IR}$ samples were stored at room temperature $\left(22^{\circ} \mathrm{C}\right)$ during the 30-day storage period. FD and FD+IR samples were rehydrated before chemical analysis and sensory evaluation after 30-day storage. For rehydration of FD and FD+IR samples, dry weight of samples were measured after storage and then appropriate amounts of hot deioinized water $\left(67^{\circ} \mathrm{C}\right)$ were added to dried samples and held for 15 min to bring the moisture contents of rehydrated meat to the same level as before freeze-drying. Volatile profiles, lipid oxidation and sensory tests were also determined after 30 days.

DETERMINATION OF VOLATILE COMPOUNDS - A purge-and-trap apparatus (Solatek 72 and Concentrator 3100; Tekmar-Dohrmann, Cincinnati, OH, USA) connected to a gas chromatograph/mass spectrometer (HP 6890/HP 5973; Hewlett-Packard Co., Wilmington, DE, USA) was used to analyze volatiles produced (Ahn et al. 2001). The minced meat sample $(2 \mathrm{~g})$ was placed in a $40-\mathrm{mL}$ sample vial, and the vial was flushed with helium gas (40 psi) for $5 \mathrm{~s}$. The maximum waiting time of a sample in a refrigerated $\left(4^{\circ} \mathrm{C}\right)$ holding tray was less than $4 \mathrm{~h}$ to minimize oxidative changes before analysis (Ahn et al. 2001). The meat sample was purged with helium gas $(40 \mathrm{~mL} / \mathrm{min})$ for $14 \mathrm{~min}$ at $40{ }^{\circ} \mathrm{C}$. Volatiles were trapped using a Tenax-charcoal-silica column (Tekmar-Dohrmann) and desorbed for $2 \mathrm{~min}$ at $225^{\circ} \mathrm{C}$, 
focused in a cryofocusing module $\left(-90^{\circ} \mathrm{C}\right)$, and then thermally desorbed into a capillary column for $60 \mathrm{~s}$ at $225^{\circ} \mathrm{C}$. An HP-624 column (8.5 m x $0.25 \mathrm{~mm}$ i.d., $1.4 \mu \mathrm{m}$ nominal), an HP-1 column ( $60 \mathrm{~m} \times 0.25 \mathrm{~mm}$ i.d., $0.25 \mu \mathrm{m}$ nominal; Hewlett-Packard), and an HP-Wax column (6.5 $\mathrm{m} \times 0.25 \mathrm{~mm}$ i.d., $0.25 \mu \mathrm{m}$ nominal) were connected using zero dead-volume column connectors ( $\mathrm{J} \& \mathrm{~W}$ Scientific, Folsom, CA, USA). Ramped oven temperature was used to improve volatile separation. The initial oven temperature of $0^{\circ} \mathrm{C}$ was held for $1.5 \mathrm{~min}$. After that, the oven temperature was increased to $15^{\circ} \mathrm{C}$ at $2.5^{\circ} \mathrm{C} / \mathrm{min}$, increased to $45^{\circ} \mathrm{C}$ at $5^{\circ} \mathrm{C} / \mathrm{min}$, increased to $110^{\circ} \mathrm{C}$ at $10^{\circ} \mathrm{C} / \mathrm{min}$, increased to $210^{\circ} \mathrm{C}$ at $20^{\circ} \mathrm{C} / \mathrm{min}$, and then was held for $3 \mathrm{~min}$ at the temperature. Constant column pressure at 22.5 psi was maintained. The ionization potential of the mass selective detector (Model 5973; Hewlett-Packard) was $70 \mathrm{eV}$, and the scan range was 19.1 to $400 \mathrm{~m} / \mathrm{z}$. Identification of volatiles was achieved by comparing mass spectral data of samples with those of the Wiley Library (Hewlett-Packard). The area of each peak was integrated using the ChemStation (HewlettPackard), and the total peak area $\left(\mathrm{pA}^{*} \mathrm{~s} \times 10^{4}\right)$ was reported as an indicator of volatiles generated from the sample.

TBARS ANALYSIS - Lipid oxidation was determined by the TBARS method (Ahn et al. 1998). Sample (5 g) was placed in a $50-\mathrm{mL}$ test tube and homogenized with 15 $\mathrm{mL}$ deionized distilled water (DDW) using a Brinkman Polytron (Type PT 10/35, Brinkman Instrument Inc., Westbury, NY, USA) for $15 \mathrm{~s}$ at high speed. The meat homogenate $(1 \mathrm{~mL})$ was transferred to a $13 \times 100 \mathrm{~mm}$ disposable glass tube and butylated hydroxyanisole (50 $\mu \mathrm{L}, 7.2 \%$ in ethanol) and thiobarbituric acid (TBA, 20 $\mathrm{mM}$ )/trichloroacetic acid (TCA, $15 \% \mathrm{wt} / \mathrm{vol}$ ) solution (2 $\mathrm{mL}$ ) were added. The mixture was vortex-mixed and then incubated in a $90^{\circ} \mathrm{C}$ water bath for $15 \mathrm{~min}$ to develop color. The sample was then cooled in cold water for $10 \mathrm{~min}$, mixed, and centrifuged for $15 \mathrm{~min}$ at 3,000 $\mathrm{x}$ $g$. The absorbance of the resulting supernatant solution was determined at $531 \mathrm{~nm}$ against a blank containing 1 $\mathrm{mL}$ deionized distilled water and $2 \mathrm{~mL}$ of TBA/TCA solution. The amounts of TBARS were expressed as milligrams of malondialdehyde (MDA) per kg meat.

SENSORY EVALUATION - The sensory evaluation was approved by the University's Human Subjects Committee and was tested in the Sensory Evaluation Unit of the Center for Designing Foods to Improve Nutrition at lowa State University. Ten trained sensory panelists characterized overall odor characteristics and texture of the samples. Panelists were selected based on interest, availability, and performance in screening tests conducted with samples similar to those to be tested. The panelists selected were trained for aroma attributes and texture characteristics of cooked hamburger patties. During training, a lexicon of aroma terms to be used on the ballot was developed and references to anchor the rating scale were identified. Before serving samples to panelists, all cooked patties were warmed in a microwave oven (Amana Radarange,
Amana, IA, USA). Freeze-dried (FD) and FD+IR patties were rehydrated before warming. Three patties were warmed on a plate that was rotated at 40-s intervals for a total of $120 \mathrm{~s}$ of heating. Patties were placed in preheated $\left(77^{\circ} \mathrm{C}\right)$ covered casserole dishes. The heated patties were cut into quarters and each participant received one piece in a covered polyfoam container labeled with a random three-digit code. Sensory panelists were asked to rate the intensity of ground beef aroma, off-aroma (irradiated), tenderness, mealiness, juiciness/moistness, cooked ground beef flavor, off-flavor (irradiated) on 15-unit linear scales (from 1: none to 15: extremely). A computerized system (Compusense five, $\mathrm{v}$ 4.0; Compusense, Inc., Guelph, Ontario, Canada) was used to input the data. Participants were instructed to rinse their mouths with water before starting to taste, and also between samples. A complete block design was used for each of the tests. Serving order was randomized.

STATISTICAL ANALYSIS - Data were analyzed using the generalized linear model procedure of SAS software (SAS Institute Inc. 1995); Student-Newman-Keul's multiple range test was used to compare the mean values of among treatments. Mean values and standard error of the means (SEM) were reported. Significance was defined at $p<0.05$.

\section{RESULTS AND DISCUSSION}

Table 1 shows the proximate analysis and cooking yield of cooked beef patties. Cooked beef patties added with fat substitute Fantesk $^{\mathrm{TM}}$ or plum extract had higher moisture content and carbohydrate, but much lower lipid content than that of control treatment with $80 \%$ lean meat. The low cook yield in high-fat beef cooked patties (control) indicated that fat was melted during cooking and lost. Fat substitute and $2 \%$ plum treatments held moisture relatively well as expected.

TBARS values of cooked beef patties at day 0 were affected by lipid contents (Table 2). After $30 \mathrm{~d}$ of storage, processing treatments were more important for TBARS values than lipid contents. The TBARS of FD+IR patties increased dramatically, whereas the IR patties were about the same as that of the nonirradiated frozen paties at day 0. FD patties illustrate some increase due to some lipid oxidation during freeze drying, which supports NASA recommendation for using nitrogen flush chambers. Ahn et al. $(1997,1998)$ reported that preventing oxygen exposure after cooking was more important for cooked meat quality than irradiation or storage time of raw meat, and lipid oxidation was a significant problem in irradiated meat only when it was stored aerobically (Merritt et al.1975; Ahn et al. 1997).

Table 3 shows the volatile compounds of non-irradiated or freeze dried cooked beef patties with different treatments at day 0 . The amounts of aldehydes, which were pentanal, hexanal, heptanal and nonanal, in $10 \%$ fat substitute Fantesk ${ }^{\mathrm{TM}}$ samples were higher than those 
of other treatment, but the amounts of total volatiles in all samples were similar at day 0 . No disulfides were detected

After $30 \mathrm{~d}$ of storage, the profiles and amounts of volatiles in cooked beef patties changed dramatically from Day 0 depending on process and treatments (Tables 4, 5 and 6). The amounts of total volatiles in frozen stored beef patties were similar to, but that of FD+IR samples were 10 times higher than non-irradiated sample at day 0 . Hexane, 2-heptene, cyclodecene and sulfur volatiles were generated by irradiation. Sulfur volatiles, which are known as the major volatile of irradiation off-odor (Ahn et al. 2000a), were detected in all irradiated samples stored under vacuum conditions for 30 days. This confirmed our previous finding that Scompounds were produced by irradiation and not volatilized rapidly under vacuum packaging conditions (Nam et al. 2002; Nam and Ahn 2003). Large amounts of aldehydes including butanal, pentanal, hexanal, heptanal and nonanal were detected in all FD+IR-treated samples. It means that the lipid oxidation process in cooked beef patties progressed during the freeze-drying step and was further accelerated during irradiation and subsequent storage. This result agrees with the TBARS values (Table 2). Shahidi and Pegg (1994) reported that aldehydes contributed the most to oxidation flavor and rancidity in cooked meat and hexanal was the predominant volatile aldehyde

Table 7 shows the sensory evaluation of cooked beef patties at day 0 and 30 . Panelists could not distinguish odor differences but easily distinguished texture differences among treatments at day 0 . Panelists characterized the overall aroma of control beef patties as "no aroma", $10 \%$ fat substitute Fantesk ${ }^{\mathrm{TM}}$-added patties as "slightly sour", $2 \%$ plum extract-added ones as "slightly sweet and fruity". After 30 day of storage, processing treatments and additives influenced the odor intensity and texture of cooked beef patties. In the control group, frozen patties had similar sensory characteristic to control samples at day 0 . Juiciness/moistness, however, was decreased in FD and FD+IR treated samples. This indicated that freeze-drying process significantly deteriorated the texture of hamburger beef patties. Sensory panelists detected irradiation odor from IR and FD+IR-treated control patties, but the off-odor intensity of FD+IR-treated meat was much higher than that of IR samples. Sensory evaluation of FD+IR-treated samples added with $10 \%$ fat substitute Fantesk ${ }^{\mathrm{TM}}$ and $2 \%$ plum extract group was not determined because most sensory panelists complained about the poor sensory quality of all FD+IR-treated samples. It was expected that the addition of fat substitute could eliminate the quality defect and improve texture and mouth feel in FD+IR hamburger beef patties. The addition of $10 \%$ fat substitute, however, had no effect on the texture, juiciness/moistness, mealiness, and tenderness of FD or FD+IR-treated beef patties. The juiciness/moistness of frozen and irradiated sample with $2 \%$ plum extract was similar to those of control even though beef with $2 \%$ plum extract used leaner meat (90\% lean meat) than control (80\% lean meat). This indicates that plum extract had a significant effect in binding moisture in the molecular structure, and maintained desirable texture and mouth feel. Sensory panelists detected lower off-odor intensity in beef patties with $2 \%$ plum extract than other treatments. Therefore, addition of $2 \%$ plum extract was effective in improving sensory characteristics of cooked hamburger beef patties.

\section{CONCLUSION}

Addition of $10 \%$ fat substitute Fantesk $^{\mathrm{TM}}$ had no influence in improving the sensory characteristics of freeze-dried (FD) or freeze-dried and irradiated (FD+IR) beef patties, but the juiciness of those was improved by plum extract. Therefore, the use of $2 \%$ plum extract is recommended to improve the mouth-feel and reduce the off-odor intensity of pre-cooked, freeze-dried hamburger beef patties. However, the effect of processing treatments on the sensory characteristics of cooked hamburger beef patties were more important than additives, and addition of fat substitute or plum extract alone was not enough to compromise the negative impact of freeze-drying and/or irradiation on the sensory characteristics of cooked beef patties. Thus NASA requirement for freeze drying in nitrogen flushed chambers and vacuum packaging under nitrogen flush are critical elements for maintaining the necessary shelflife requirements for processed meat products for space exploration.

\section{ACKNOWLEDGMENT}

This work was supported by the Great Lakes Industrial Technology Center (GLITeC) BATTELLE (Cleveland, $\mathrm{OH}$ ), the NASA Food Technology Commercial Space Center at lowa State University (Ames, IA.), and the lowa Agricutlure and Home Economics Experiment Station. Sensory evaluations were directed by Cynthia Shriver with the Sensory Evaluation Unit of the Center for Designing Foods to Improve Nutrition at lowa State University.

\section{REFERENCES}

1. Ahn, DU, Sell JL, Jeffery M, Jo C, Chen X, Wu C, Lee Jl. 1997. Dietary vitamin $E$ affects lipid oxidation and total volatiles of irradiated raw turkey meat. J Food Sci 62(5):954-959.

2. Ahn DU, Olson DG, Jo C, Chen X, Wu C, Lee JI. 1998. Effect of muscle type, packaging, and irradiation on lipid oxidation, volatile production, and color in raw turkey patties. Meat Sci 47(1):27-39.

3. Ahn DU, Jo C, Du M, Olson DG, Nam KC. 2000. Quality characteristics of pork patties irradiated and stored in different packaging and storage conditions. Meat Sci 56(2):203-209.

4. Anon C. 2000. Not a prune, more a dried plum, International Food Ingredients (6):37-38. 
5. Decker KJ. 1999. Designing moister meat: a plum assignment .Food Product Design.

6. Garzon GA, Gaines CS, Palmquist DE. 2003. Use of wheat flour-lipid and waxy maize starch-lipid composites in wire-cut formula cookies. Journal of Food Science 68(2):654-659.

7. Josephson ES, Peterson MS. 2000. Preservation of food by ionizing radiation (I). CRC Press, Boca Raton, Florida. p 172-186.

8. Keeton JT, Rhee KS, Boleman RM, Nunez MT. 2001. Antioxidant properties of dried plum ingredients in fresh and precooked pork sausage. A final report to the California Dried Plum Board. P 2-3.

9. Merritt, C. Jr., P. Angelini, E. Wierbicki, and G.W. Shuts, 1975. Chemical changes associated with flavor in irradiated meat. J. Agric. Food Chem. 23:1037-1043.

10. Murano PS. 1995. Quality of irradiated foods. In: Murano EA, editor. Food irradiation: A source book. Ames, IA: lowa State University Press. 89-126.

11. Nam KC, Ahn DU. 2003. Use of antioxidants to reduce lipid oxidation and off-odor volatiles of irradiated pork homogenates and patties. Meat Sci 63(1):1-8.

12. Nam KC, Du M, Jo C, Ahn DU. 2002. Effect of ionizing radiation on quality characteristics of vacuumpackaged normal, pale-soft-exudative, and dark-firm-dry pork. Innovative Food Science and Emerging Technologies 3(1): 73-79.

13. O'Connell MJ, Garner A. 1983. Radiation-induced generation and properties of lipid hydroperoxide in liposomes. Int J Radiat Biol 44:615-625.

14. SAS Institute Inc. 1995. SAS/STAT User's Guide. Cary, NC: SAS Institute Inc.

15. Shahidi F, Pegg RB. 1994. Hexanal as an indicator of the flavor deterioration of meat and meat products. In "Lipids in Food Flavors". ACS Sym Ser 558. Washington, DC. Am Chem Soc p256.

16. Thakur BR, Singh RK. 1994. Food irradiationchemistry and applications. Food Rev Int 10 (4):437-473. 17. Woods RJ, Pikaev AK. 1994. Interaction of radiation with matter. In: Woods RJ, Pikaev AK. Applied radiation chemistry: radiation processing. New York: John Wiley \& Sons. P 59-89. 
Table 1. Proximate analysis of cooked beef patties at day 0.

\begin{tabular}{|c|c|c|c|c|c|c|}
\hline & Protein & Moisture & Ash & Lipid & Carbohydrate & $\frac{\text { (unit: \%) }}{\text { Cooking vield }}$ \\
\hline Con & $25.43 \pm 0.03$ & $58.40 \pm 1.48$ & $0.96 \pm 0.06$ & $14.55 \pm 0.39$ & 0.66 & 70.99 \\
\hline $\begin{array}{l}10 \% \text { Fantesk }^{\mathrm{TM}} \\
2 \% \text { plum }\end{array}$ & $\begin{array}{l}26.17 \pm 0.21 \\
24.58(0.23\end{array}$ & $\begin{array}{l}63.43 \pm 0.30 \\
64.82(0.63\end{array}$ & $\begin{array}{l}1.03(0.02 \\
1.04(0.02\end{array}$ & $\begin{array}{l}8.58(0.49 \\
7.71(0.32\end{array}$ & $\begin{array}{l}0.80 \\
1.85\end{array}$ & $\begin{array}{l}73.75 \\
72.94\end{array}$ \\
\hline
\end{tabular}

For proximate analyses, $\mathrm{n}=8$; for cook yield, $\mathrm{n}=64$.

Control was $80 \%$ lean whereas amended patties were with $90 \%$ lean beef

Table 2. TBARS of cooked beef patties at day 0 and day $30 . \quad$ (unit: MDA mg/ $\mathrm{kg}$ meat.)

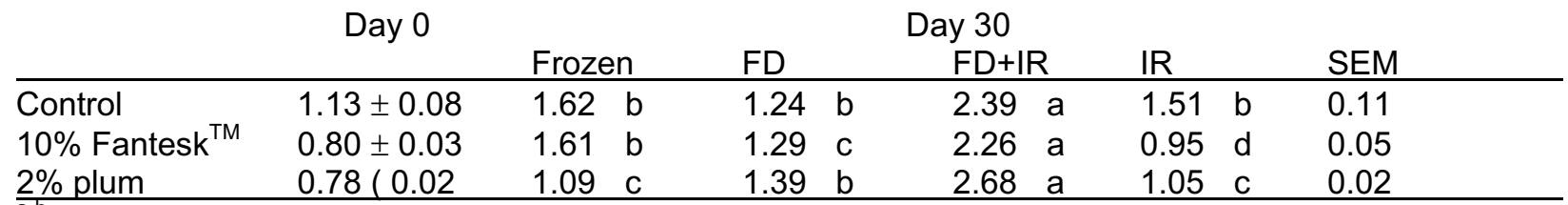

${ }^{a-b}$ Values with different letters within a row with the same irradiation dose are significantly different $(P<0.05)$.

SEM: standard error of the means. $n=4$.

FD is freeze-drying, IR is irradiation, and FD+IR is combination of freeze-drying and irradiation.

Control was $80 \%$ lean whereas amended patties were with $90 \%$ lean beef

Table 3. Volatile profiles of cooked beef patties at day 0.

\begin{tabular}{|c|c|c|c|c|c|c|c|}
\hline \multirow[b]{3}{*}{ Pentane } & \multicolumn{3}{|c|}{ 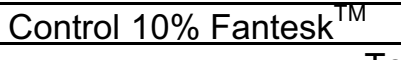 } & \multicolumn{3}{|c|}{$2 \%$ plum SEM } & \\
\hline & & & --- To & al io & $5 \times 10^{4}$ & & \\
\hline & 2121 & b & 3372 & a & 2095 & $b$ & 230 \\
\hline 2-Propanone & 11017 & b & 16834 & a & 15631 & a & 961 \\
\hline Ethanol & 2003 & b & 1582 & b & 4679 & a & 229 \\
\hline 2-Butanone & 719 & b & 1010 & a & 680 & $b$ & 55 \\
\hline Heptane & 592 & b & 874 & a & 461 & $b$ & 57 \\
\hline Pentanal & 828 & b & 2672 & a & 1054 & b & 165 \\
\hline Trimethyl pentane & 2188 & a & 1403 & b & 1306 & $b$ & 149 \\
\hline 3-Methyl heptane & 1029 & & 999 & & 635 & & 111 \\
\hline 1-Octene & 732 & a & 511 & b & 499 & $b$ & 58 \\
\hline Octane & 5109 & a & 4365 & $a b$ & 3355 & b & 389 \\
\hline 2-Octene & 2544 & a & 1826 & b & 1818 & $b$ & 177 \\
\hline Hexanal & 5136 & b & 13641 & a & 7816 & b & 865 \\
\hline 1-Pentanol & 1466 & b & 2250 & a & 1638 & $b$ & 140 \\
\hline Heptanal & 364 & b & 922 & a & 347 & $\mathrm{~b}$ & 74 \\
\hline 3-Methyl undecane & 1430 & a & 1914 & a & 568 & $b$ & 283 \\
\hline 1-Decyne & 2307 & b & 3553 & a & 1810 & $b$ & 353 \\
\hline Dimethyl trisulfide & 1144 & ab & 1555 & $\mathbf{a}$ & 625 & b & 230 \\
\hline 1-Octene-3-ol & 646 & & 908 & & 1118 & & 161 \\
\hline Nonanal & 530 & & 892 & & 679 & & 98 \\
\hline Total & 41907 & & 61085 & & 46812 & & \\
\hline
\end{tabular}

${ }^{a-b}$ Values with different letters within a row with the same irradiation dose are significantly different $(P<0.05)$.

SEM is standard error of the means. $n=4$.

Control was $80 \%$ lean whereas amended patties were with $90 \%$ lean beef. 
Table 4. Volatile profiles of control ( $80 \%$ lean) beef patties with different processing treatments at day 30.

\begin{tabular}{|c|c|c|c|c|c|c|c|c|}
\hline \multirow{2}{*}{ Acetaldehyde } & \multicolumn{2}{|c|}{ Frozen } & \multicolumn{2}{|l|}{ FD } & \multicolumn{2}{|c|}{ IRFD+IR } & \multicolumn{2}{|l|}{ SEM } \\
\hline & 0 & b & 0 & $\mathrm{~b}$ & $\begin{array}{l}\text { al ion cou } \\
0\end{array}$ & $b$ & $23420 a$ & 1641 \\
\hline Pentane & $1606 c$ & & 4276 & c & 33436 & $a$ & $17217 b$ & 2633 \\
\hline 2-Propanone & $8679 k$ & & 12889 & $b$ & 13987 & & $57641 a$ & 2523 \\
\hline 1-Propanol & $1077 k$ & & 0 & c & 3149 & a & $1361 b$ & 96 \\
\hline 2-Methyl propanal & 0 & d & 2128 & c & 6004 & b & $14858 a$ & 540 \\
\hline 3-Methyl pentane & 0 & c & 0 & c & 1978 & b & 4952 a & 416 \\
\hline 1-Hexene & $4563 a$ & & 3947 & a & 1328 & b & 0 & 228 \\
\hline Ethanol & $823 k$ & b & 1009 & b & 0 & b & $39098 a$ & 761 \\
\hline Hexane & 0 & c & 0 & c & 62656 & $a$ & $23577 b$ & 2790 \\
\hline Butanal & 0 & b & 775 & b & 2163 & a & 2808 a & 258 \\
\hline 2-Butanone & $350 k$ & b & 3161 & b & 6034 & b & $60477 a$ & 2032 \\
\hline 2,3-Butadione & 0 & c & 722 & b & 0 & c & $1632 a$ & 151 \\
\hline 3-Methyl butanal & 0 & d & 2439 & c & 5358 & b & $20353 a$ & 568 \\
\hline 2-Methyl butanal & 0 & c & 1618 & c & 6303 & b & $13933 a$ & 966 \\
\hline 1-Heptene & 0 & c & 185 & c & 8539 & b & $11772 a$ & 788 \\
\hline Heptane & $955 \mathrm{c}-r-2$ & c & 1107 & c & 38589 & & $25870 \mathrm{~b}$ & 2983 \\
\hline Pentanal & 670 & c & 4483 & b & 3843 & b & 6690 a & 471 \\
\hline 2-Heptene & 0 & b & 0 & b & 1414 & a & 1792 a & 177 \\
\hline 4-Methyl-2-pentanone & $1475 \mathrm{k}$ & & 0 & c & 1951 & a & $1372 \mathrm{~b}$ & 88 \\
\hline Dimethyl disulfide & 613 & b & 3607 & b & 3806 & b & $36394 a$ & 1944 \\
\hline Toluene & $306 c$ & c & 508 & c & 6796 & b & $22369 a$ & 753 \\
\hline Octane & $4422 k$ & & 1681 & b & 50156 & $a$ & $43021 a$ & 4402 \\
\hline Hexanal & $6389 c$ & & 22142 & $a$ & 11618 & $b$ & $17901 a$ & 1384 \\
\hline 3-ethyl heptane & 0 & c & 165 & c & 796 & b & 1163 a & 116 \\
\hline Nonane & $115 \mathrm{c}$ & c & 253 & c & 11007 & b & $16370 a$ & 648 \\
\hline 1-Pentanol & 1279 & & 1488 & & 1652 & & 1414 & 92 \\
\hline 2-Heptanone & 0 & d & 376 & c & 810 & b & 1134 a & 58 \\
\hline Heptanal & $400 \mathrm{c}-\mathrm{c}-\mathrm{r}$ & c & 1196 & b & 4305 & a & $1826 \mathrm{~b}$ & 212 \\
\hline 3-Methyl undecane & 782 & c & 2731 & $a b$ & 1859 & b & 3469 a & 302 \\
\hline 3-Methyl nonane & $270 k$ & b & 929 & a & 647 & a & 1013 a & 100 \\
\hline Decene & $436 \mathrm{c}-r-r)$ & c & 1320 & c & 4540 & b & $12425 a$ & 388 \\
\hline 3-Octanone & $434 \mathrm{c}-r-r)$ & c & 1018 & $\mathrm{bc}$ & 4933 & a & $1479 \mathrm{~b}$ & 193 \\
\hline 2-Octanone & $1396 \mathrm{k}$ & & 3673 & a & 4599 & a & 3645 a & 321 \\
\hline 1-Decyne & $1294 c$ & & 3623 & b & 3367 & b & 5343 a & 409 \\
\hline Dimethyl trisulfide & 0 & b & 0 & b & 345 & b & 8648 a & 534 \\
\hline Undecane & 0 & c & 0 & c & 2190 & b & 4092 a & 186 \\
\hline 1-Octene-3-ol & $694 k$ & b & 2125 & a & 1172 & b & 1854 a & 177 \\
\hline Nonanal & $759 k$ & b & 2239 & b & 1803 & b & 6989 a & 418 \\
\hline 2-Ethyl-1-hexanol & $398 c$ & c & 465 & c & 4012 & a & $3104 b$ & 195 \\
\hline Cyclodecene & 0 & c & 0 & c & 245 & b & 1008 a & 54 \\
\hline 3-Methyl benzaldehyde & $1968 k$ & & 3142 & a & 0 & d & $991 \mathrm{c}$ & 260 \\
\hline Total & 42152 & & 91423 & & 31739 & & 52477 & \\
\hline
\end{tabular}

${ }^{\mathrm{a}-\mathrm{d}}$ Values with different letters within a row with the same irradiation dose are significantly different $(P<0.05)$. SEM is standard error of the means. $n=4$.

FD is freeze-drying, IR is irradiation, and FD+IR is combination of freeze-drying and irradiation. 
Table 5. Volatile profiles of $10 \%$ fat substituted Fantesk ${ }^{\mathrm{TM}}$ added beef patties with different processing treatments at day 30 .

\begin{tabular}{|c|c|c|c|c|c|c|c|}
\hline & Frozen & FD & & $\mathrm{IR}$ & & FD+IR & SEM \\
\hline Acetaldehvde & $261 \mathrm{c}$ & 3769 & $h$ & ion count & th $\times 1$ & 32003 & 557 \\
\hline Pentane & $2218 c$ & 3636 & $\mathrm{c}$ & $23627 a$ & & $18465 b$ & 1211 \\
\hline 2-Propanone & $8598 c$ & 12819 & & $24912 b$ & & $61745 a$ & 1405 \\
\hline 1-Propanol & $1273 c$ & 0 & d & $3398 a$ & a & $1445 b$ & 55 \\
\hline 2-Methyl propanal & 0 & 3168 & c & $9636 \mathrm{~b}$ & b & $15207 a$ & 218 \\
\hline 3-Methyl pentane & 0 & 0 & c & $2154 \mathrm{~b}$ & b & 4646 a & 230 \\
\hline 1-Hexene & 0 & 0 & c & 975 & a & $527 \quad b$ & 128 \\
\hline Ethanol & $5193 b$ & 4410 & b & 0 & c & $31340 a$ & 924 \\
\hline Hexane & 0 & 0 & c & $61785 a$ & & $23328 b$ & 1250 \\
\hline Butanal & 0 & 1106 & b & $2707 a$ & a & 2767 a & 271 \\
\hline 2-Butanone & $732 \mathrm{c}$ & 3618 & c & $13005 b$ & & $59813 a$ & 1044 \\
\hline 2,3-Butadione & 0 & 990 & b & 0 & c & 1490 a & 57 \\
\hline 3-Methyl butanal & 0 & 3810 & c & $7984 \mathrm{~b}$ & b & $23374 a$ & 250 \\
\hline 2-Methyl butanal & 0 & 2338 & c & $13330 \mathrm{~b}$ & & $15796 a$ & 199 \\
\hline 1-Heptene & 0 & 137 & b & $6960 a$ & a & 6077 a & 287 \\
\hline Heptane & $1003 c$ & 879 & c & $31032 a$ & & $15997 b$ & 1251 \\
\hline Pentanal & $1493 d$ & 8256 & b & $5241 \mathrm{c}$ & c & $10165 a$ & 512 \\
\hline 2-Heptene & 0 & 293 & c & 960 & b & $1252 a$ & 39 \\
\hline 4-Methyl-2-pentanone & $872 \mathrm{c}$ & 0 & d & $1625 \mathrm{~b}$ & b & 2360 a & 73 \\
\hline Dimethyl disulfide & $517 \mathrm{c}$ & 5537 & b & $4447 b$ & b & $28887 a$ & 899 \\
\hline Toluene & $317 \mathrm{c}$ & 649 & c & $10266 \mathrm{~b}$ & & $25888 a$ & 350 \\
\hline Octane & $3521 \mathrm{c}$ & 1047 & c & $42057 \mathrm{a}$ & & $21938 b$ & 1202 \\
\hline Hexanal & $8734 d$ & 40123 & $a$ & $17202 c$ & & $25235 b$ & 2159 \\
\hline 3-ethyl heptane & 0 & 209 & b & 998 & a & 1139 a & 58 \\
\hline Nonane & $151 \mathrm{~b}$ & 276 & b & $10023 a$ & & $10303 a$ & 309 \\
\hline 1-Pentanol & $1454 c$ & 2227 & a & $2126 a$ & $a b$ & $1855 \mathrm{~b}$ & 95 \\
\hline 2-Heptanone & $282 d$ & 743 & c & 997 & b & $1819 a$ & 49 \\
\hline Heptanal & $698 d$ & 2245 & c & $6272 a$ & a & $3272 b$ & 322 \\
\hline 3-Methyl undecane & $1006 b$ & 3805 & a & $3111 a$ & a & 3257 a & 252 \\
\hline 3-Methyl nonane & $327 b$ & 1292 & a & $1067 a$ & a & $1030 a$ & 100 \\
\hline Decene & $477 \mathrm{c}$ & 2428 & b & $9495 a$ & a & $10227 a$ & 277 \\
\hline 3-Octanone & $985 \mathrm{~b}$ & 863 & b & $1320 \mathrm{~b}$ & b & 2084 a & 172 \\
\hline 2-Octanone & $1648 c$ & 5164 & b & 6596 a & a & $4172 \mathrm{~b}$ & 461 \\
\hline 1-Decyne & $1892 b$ & 5444 & a & 5145 a & a & 5664 a & 411 \\
\hline Dimethyl trisulfide & 0 & 608 & b & 561 & b & 7295 a & 303 \\
\hline Undecane & 0 & 0 & c & $2537 \mathrm{~b}$ & b & 4043 a & 106 \\
\hline 1-Octene-3-ol & $934 \mathrm{c}$ & 2778 & a & $1711 \mathrm{~b}$ & b & $2874 a$ & 195 \\
\hline Nonanal & $1196 \mathrm{c}$ & 3405 & b & $3010 \mathrm{~b}$ & b & $10104 a$ & 167 \\
\hline 2-Ethyl-1-hexanol & $466 \mathrm{c}$ & 389 & c & 4693 a & a & $3404 \mathrm{~b}$ & 78 \\
\hline Cyclodecene & 0 & 0 & c & 276 & b & 632 & 13 \\
\hline 3-Methyl benzaldehyde & $1154 b$ & 1974 & a & 300 & c & 661 & 130 \\
\hline Total & 47405 & 13043 & & 344672 & & 503580 & \\
\hline
\end{tabular}

${ }^{a-d}$ Values with different letters within a row with the same irradiation dose are significantly different $(P<0.05)$. SEM is standard error of the means. $n=4$.

FD is freeze-drying, IR is irradiation, and FD+IR is combination of freeze-drying and irradiation. 
Table 6 . Volatile profiles of cooked $2 \%$ plum extract-added beef patties with different processing treatments at day 30 .

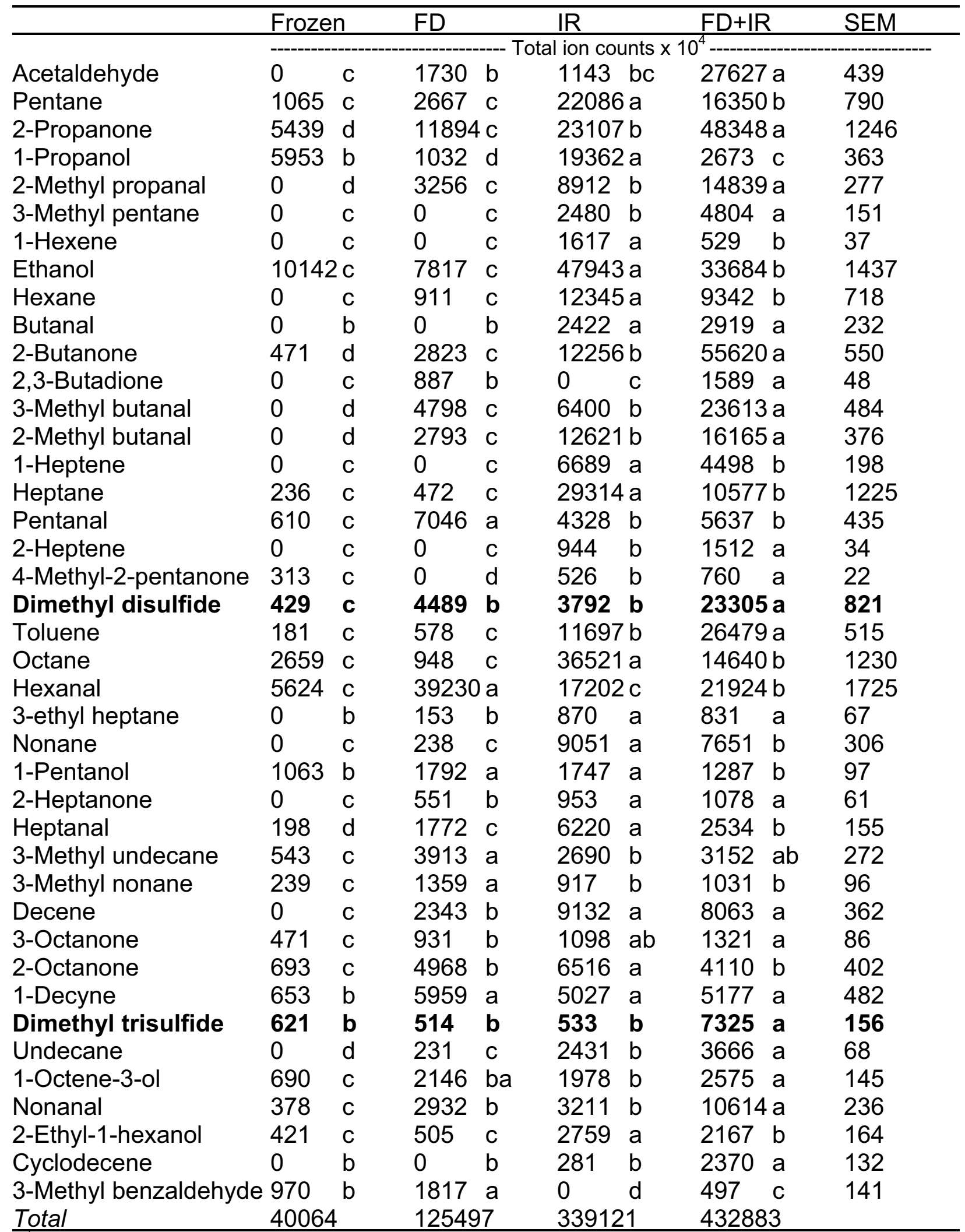

${ }^{a-d}$ Values with different letters within a row with the same irradiation dose are significantly different $(P<0.05)$. SEM is standard error of the means. $n=4$.

FD is freeze-drying, IR is irradiation, and FD+IR is combination of freeze-drying and irradiation. 
Table 7. Sensory evaluation of cooked beef patties at day 0 and day 30 .

Day 0 (Non irradiated sample)
Ground Beef Aroma
Tenderness
Mealiness
Juiciness/Moistness
Cooked Ground Beef Flavor
Off-Flavor

$\underline{\text { Day } 30}$

Ground Beef Aroma

Off-Aroma (irradiated)

Tenderness

\begin{tabular}{llll} 
Control & $10 \%$ Fantesk $^{\mathrm{TM}}$ & $2 \%$ plum & SEM \\
\hline 6.18 & 6.17 & 4.21 & 0.81 \\
$9.87 \mathrm{~b}$ & $11.10 \mathrm{ab}$ & $11.91 \mathrm{a}$ & 0.51 \\
$3.85 \mathrm{~b}$ & $10.61 \mathrm{a}$ & $11.26 \mathrm{a}$ & 0.60 \\
$6.00 \mathrm{a}$ & $2.29 \mathrm{~b}$ & $2.77 \mathrm{~b}$ & 0.54 \\
$7.74 \mathrm{a}$ & $5.28 \mathrm{~b}$ & $3.72 \mathrm{~b}$ & 0.74 \\
$0.20 \mathrm{~b}$ & $0.65 \mathrm{ab}$ & $1.23 \mathrm{a}$ & 0.26
\end{tabular}

Mealiness

Juiciness/Moistness

Cooked Ground Beef Flavor

Off-Flavor (irradiated)

\begin{tabular}{|c|c|c|c|c|c|}
\hline & & \multicolumn{3}{|l|}{ Control } & \\
\hline Frozen & FD & IR & FD+IR & SEM & \\
\hline $8.80 \mathrm{a}$ & $7.35 \mathrm{a}$ & $6.42 \mathrm{a}$ & $1.15 \mathrm{~b}$ & 0.72 & \\
\hline $0.21 \mathrm{c}$ & $1.41 \mathrm{c}$ & $3.55 \mathrm{~b}$ & 12.83 & a & 0.53 \\
\hline 10.21 & 6.12 & 10.88 & 10.45 & a & 0.62 \\
\hline $2.54 \mathrm{C}$ & $3.88 \mathrm{c}$ & $7.21 \mathrm{~b}$ & 10.16 & a & 0.75 \\
\hline $8.37 \mathrm{a}$ & $3.42 \mathrm{c}$ & $6.69 \mathrm{~b}$ & $2.73 \mathrm{c}$ & 0.56 & \\
\hline $8.34 \mathrm{a}$ & $7.02 \mathrm{a}$ & $5.21 b$ & $1.05 \mathrm{c}$ & 0.6 & \\
\hline $0.21 \mathrm{c}$ & $0.68 \mathrm{c}$ & $4.41 \mathrm{~b}$ & 12.25 & a & 0.5 \\
\hline
\end{tabular}

Ground Beef Aroma
Off-Aroma (irradiated)
Tenderness
Mealiness
Juiciness/Moistness
Cooked Ground Beef Flavor
Off-Flavor (irradiated)

\begin{tabular}{|c|c|c|c|c|c|}
\hline Control & & t substit & Fantesk & & \\
\hline Frozen & Frozen & $\mathrm{FD}$ & IR & SEM & \\
\hline $9.23 \mathrm{a}$ & $4.18 \mathrm{~b}$ & $2.68 \mathrm{~b}$ & $2.56 \mathrm{~b}$ & 0.74 & \\
\hline $0.54 \mathrm{c}$ & $2.87 \mathrm{bc}$ & $5.60 a b$ & $8.11 \mathrm{a}$ & 1.03 & \\
\hline 9.31 & 9.75 & 7.53 & 9.15 & 1.12 & \\
\hline $1.24 \mathrm{C}$ & $7.49 \mathrm{~b}$ & $8.41 \mathrm{~b}$ & 11.98 & a & 0.85 \\
\hline $8.74 \mathrm{a}$ & $3.90 \mathrm{~b}$ & $2.92 \mathrm{~b}$ & $1.65 \mathrm{~b}$ & 0.68 & \\
\hline $8.28 \mathrm{a}$ & $5.76 \mathrm{~b}$ & $4.25 \mathrm{~b}$ & $1.62 \mathrm{c}$ & 0.63 & \\
\hline $0.22 \mathrm{c}$ & $0.95 \mathrm{c}$ & $3.48 \mathrm{~b}$ & $8.70 \mathrm{a}$ & 0.7 & \\
\hline
\end{tabular}

Ground Beef Aroma

\begin{tabular}{llllll}
\hline Control & \multicolumn{5}{l}{$2 \%$ plum extract } \\
\cline { 2 - 5 } Frozen & Frozen & FD & IR & SEM \\
\hline $8.36 \mathrm{a}$ & $5.35 \mathrm{~b}$ & $3.61 \mathrm{~b}$ & $5.64 \mathrm{~b}$ & 0.68 \\
$0.34 \mathrm{~b}$ & $1.27 \mathrm{~b}$ & $4.24 \mathrm{a}$ & $3.85 \mathrm{a}$ & 0.56 & \\
$8.57 \mathrm{~b}$ & $12.1 \mathrm{a}$ & $7.14 \mathrm{~b}$ & 12.48 & $\mathrm{a}$ & 0.69 \\
$1.38 \mathrm{~d}$ & $4.69 \mathrm{c}$ & $6.92 \mathrm{~b}$ & 10.48 & $\mathrm{a}$ & 0.68 \\
$7.89 \mathrm{a}$ & $7.15 \mathrm{ab}$ & $2.58 \mathrm{c}$ & $5.35 \mathrm{~b}$ & 0.64 & \\
$8.40 \mathrm{a}$ & $4.90 \mathrm{~b}$ & $3.54 \mathrm{bc}$ & $2.68 \mathrm{c}$ & 0.62 \\
$0.31 \mathrm{~b}$ & $1.92 \mathrm{~b}$ & $5.03 \mathrm{a}$ & $6.56 \mathrm{a}$ & 0.67 &
\end{tabular}

Off-Aroma (irradiated)

Tenderness

Mealiness

Juiciness/Moistness

Cooked Ground Beef Flavor

Off-Flavor (irradiated)

${ }^{a-c}$ Values with different letters within a row with the same irradiation dose are significantly different $(P<0.05)$.

SEM is standard error of the means. $n=4$.

Sensory characteristics: 0 , none; 15 , extremely high.

FD is freeze-drying, IR is irradiation, and FD+IR is combination of freeze-drying and irradiation.

Control was $80 \%$ lean whereas all amended patties were $90 \%$ lean 